\title{
Fistulojejunostomy in the Management of Chronic External Biliary Fistula
}

\section{Kemal Atahan*, Atilla Çökmez, Evren Durak and Ercüment Tarcan}

Izmir Ataturk Training and Research Hospital, $1^{\text {st }}$ Surgical Department, Izmir, Turkey

\begin{abstract}
Aim: We have recently used an alternative surgical method to resolve external chronic refractory biliary fistula (ECRBF) and in this article we described our experience with external chronic refractory biliary fistula.

Methods: We reviewed the records of patients who underwent ECRBF between 2000 and 2009. Since conservative or endoscopic management methods were not useful, fistulojejunostomy was the treatment of choice for these patients. Patients' demographics, operation details, clinical and pathological findings and follow up data were retrieved.

Results: We identified 12 patients ( 7 were female and 5 male, with a mean age of 47 years; range, 33 to 64 years) who had external chronic refractory biliary fistulas managed by fistulojejunostomy. All patients were admitted with obvious external bile fistulas with an average duration of 24 weeks (range 20 to 36 weeks). The fistulas were confirmed by PTC fistulography, ERCP and also MRCP in all patients. The fistulas occurred following cholecystectomy and bile duct exploration in 5 patients, liver hydatic surgery in 3, choledochojejunostomy anastomotic leak after Whipple procedure in 2 and liver trauma in 2 patients. The mean fistula output was measured as $573 \mathrm{cc}$ per day. Follow up time is 49 weeks average.
\end{abstract}

Conclusions: In this report we described our experience with fistulojejunostomy in the treatment of external chronic refractory biliary fistula when conventional surgical and minimal invasive approaches fail. Fistulojejunostomy can be considered as a viable alternative for the patients with external chronic refractory biliary fistula in those cases not amenable for conventional surgical or mininvasive procedures.

Keywords: Fistulojejunostomy; Biliary fistula; ERCP; Surgery; Anastomosis

\section{Introduction}

The improvements in surgical and minimal invasive endoscopic techniques has resulted a substantial reduction in the incidence of biliary complications of hepatobiliary surgery. Nevertheless post cholecystectomy complications are still a major concern as a cause of morbidity and mortality. Of these, external chronic refractory biliary fistula $(\mathrm{ECRBF})$ can occur after cholecystectomy, liver surgery and trauma.

The incidence of external chronic refractory biliary fistula has been reported in the literature in the range of 0 to $5 \%[1,2]$ following major hepatobiliary surgery. Also injuries to the bile duct during both laparoscopic and open cholecystectomy seem to increase its incidence recently. This injury generally results from imprecise dissection and inadequate demonstration of the biliary structures [3]. This catastrophic situation may be preventable but once occurred it often necessitates repeated surgical and endoscopic interventions and an estimated mortality rates approaching $20 \%[2,4]$.

ECRBF can be associated with morbidities, including cholangitis, metabolic derangements, hemorrhage and sepsis. When conventional surgical and endoscopic methods fail fistulojejunostomy seems like to be the last viable option to establish bilioenteric continuity.

At the Izmir Ataturk Training and Research Hospital, we have recently used an alternative surgical method to resolve ECRBF and in this article we described our experience with external chronic refractory biliary fistula.

\section{Material and Methods}

\section{Patients}

We reviewed the records of patients who underwent ECRBF in İzmir Atatürk Training and Research Hospital 1st Department of Surgery between 2000 and 2009. Institutional Review Board approval was obtained to use our clinical database for this period to identify these patients. Patients' demographics, operation details, clinical and pathological findings and follow up data were retrieved. Duration of hospital stay and complications were also included.

The benefits of biliary stenting in healing of external biliary fistula have been described previously. Unfortunately following localization of the site of fistula, therapeutic sphincterotomy and biliary stenting were not feasible for our patients since anatomical derangements did not allow us to cannulate bile ducts properly. Computed tomography was carried out in all patients and interventional radiology was consulted for the possibility of percutaneous drains. Biologic glues were not tried for fistula tract ablation. Since conservative or endoscopic management methods were not useful, fistulojejunostomy was the treatment of choice for these patients.

\section{Surgery}

During exploration, the fistula tract was carefully dissected and freed from the adjunct tissues. Meticulous attention was focused to save continuity of that scar tissue. This tubular structure was transected right below the abdominal wall and the distal end of fistula was prepared for end to side anastomosis. During that stage the patency of fistula tract was checked by inserting a plastic cannula through the

*Corresponding author: Kemal Atahan, 6342 sok. No: 44 Ayşe Kaya 2 Apt Kat: 3, Daire: 6 35540, Bostanlı, Izmir, Turkey, Tel: 90-532-412-6805; Fax: 90232-244-5624; E-mail: kemalatahan@yahoo.com.tr

Received December 02, 2011; Accepted February 04, 2012; Published February 06, 2012

Citation: Atahan K, Çökmez A, Durak E, Tarcan E (2012) Fistulojejunostomy in the Management of Chronic External Biliary Fistula. Surgery 2:108. doi:10.4172/21611076.1000108

Copyright: ( 2012 Atahan K, et al. This is an open-access article distributed under the terms of the Creative Commons Attribution License, which permits unrestricted use, distribution, and reproduction in any medium, provided the original author and source are credited. 
tract. Following the dissection of fistula tract, a Roux en Y limb was prepared in a conventional way. The end-to-side fistulojejunostomy was fashioned with interrupted 4-0 absorbable sutures. Silicone stents were routinely placed through the fistulojejunostomy anastomosis and stayed for 3 weeks postoperatively. The anastomosis was also secured by additional simple interrupted sutures between the external surface of fistula and serozal part of jejunum. Intra-abdominal drain was placed in all patients. The old fistula tract inside the abdominal wall was debrided and left for secondary healing.

\section{Results}

We identified 12 patients ( 7 were female and 5 male, with a mean age of 47 years; range, 33 to 64 years) who had external chronic refractory biliary fistulas managed by fistulojejunostomy. All patients were admitted with obvious external bile fistulas with an average duration of 6 months (range 5 to 9 months). The fistulas were confirmed by PTC fistulography, ERCP and also MRCP in all patients. The demographics, etiology of external biliary fistula, duration of fistula are as shown in Table 1.

The fistulas occurred following cholecystectomy and bile duct exploration in 5 patients, liver hydatic surgery in 3, choledochojejunostomy anastomotic leak after Whipple procedure in 2 and liver trauma in 2 patients. The mean fistula output was measured as $573 \mathrm{cc}$ per day (Range $400-8000 \mathrm{cc}$ ). The postoperative course was uneventful in 8 patients; average hospital stay for these patients was 8 days. Two patients had wound infections responded well to drainage and careful debridement. One patient had left side pneumonia and this was successfully treated with additional antibiotics. One patient had bile drainage through the abdominal drain placed next to anastomosis for 14 days postoperatively (volume $50 \mathrm{cc}$ ) and this leak was stopped spontaneously without any intervention.

One patient had suffered slightly deteriorated renal functions postoperatively and the cause was not identified. The renal functions returned to normal after close follow up and proper hydration.

The average operative time was 2 hours and 15 minutes; three patients needed blood transfusions preoperatively. There were no intraoperative complications. There was no mortality in all patients.

12 patients were followed for average of 49 months. Of these 12 patients, 6 needed hospital admissions for the treatment of cholangitis. 2 patients had 3 consecutive cholangitis attacks and they were successfully treated with IV antibiotics.

MRCP was performed in these 12 patients 6 months after the operation and there were no apparent dilatation of intrahepatic biliary ducts in 9 patients. A moderate dilatation of intrahepatic biliary ducts was detected in 3 cases but these patients have been dealing well and their blood chemistry has shown slightly increased liver function tests.

\section{Discussion}

The external chronic refractory biliary fistula (ECRBF) is a very rare problem in surgical practice; however these patients are referred to high volume centers from district hospitals especially following difficult laparoscopic cholecystectomy operations. The incidence of external chronic refractory biliary fistula has been reported as $2 \%$ following major hepatic surgery $[3,4]$. However there were reports recently stating the incidence may increase with the wider use of laparoscopic cholecystectomy.

Most of the chronic fistulas occur as a result of sophisticated hepatobiliary procedures in the modern era. These patients almost have had additional interventions like ERCP, percutaneous drainages, biliary stenting etc. When patients fail to respond those alternatives, fistulojejunostomy seems to be last but most viable choice to treat the chronic fistula.

Interestingly the patients with external chronic refractory biliary fistula are dealing well with that situation since low volume bile deficit do not cause life threatening disturbances. On the other hand they were first approached conservatively; and that method has been found effective in $70 \%$ of these patients. Our patient group belongs to remaining $30 \%$ of external chronic refractory biliary fistula patients. The median time of spontaneous closure is reported between 4 to 36

\begin{tabular}{|c|c|c|c|c|c|c|c|c|c|}
\hline $\begin{array}{l}\text { Patient } \\
\text { Number }\end{array}$ & Sex & Age & Etiology of Fistula & $\begin{array}{l}\text { Duration } \\
\text { of Fistula } \\
\text { (Weeks) }\end{array}$ & $\begin{array}{l}\text { Fistula } \\
\text { Output (cc) }\end{array}$ & Operative Time & Morbidity & $\begin{array}{l}\text { Duration of } \\
\text { Hospital Stay } \\
\text { (days) }\end{array}$ & $\begin{array}{l}\text { Postoperative } \\
\text { Follow-up } \\
\text { (months) }\end{array}$ \\
\hline 1 & $\mathrm{~F}$ & 42 & $\begin{array}{l}\text { Choledochojejunostomy anastomic } \\
\text { leak after whipple procedure }\end{array}$ & 26 & 530 & $1 \mathrm{~h}, 50 \mathrm{~min}$ & No event & 8 & 120 \\
\hline 2 & M & 52 & $\begin{array}{l}\text { Cholecystectomy and bile duct } \\
\text { exploration }\end{array}$ & 20 & 400 & $2 \mathrm{~h}, 50 \mathrm{~min}$ & No event & 9 & 24 \\
\hline 3 & $\mathrm{~F}$ & 33 & Liver hydatic surgery & 23 & 620 & $2 \mathrm{~h}, 15 \mathrm{~min}$ & Bile drainage & 14 & 36 \\
\hline 4 & $\mathrm{~F}$ & 47 & $\begin{array}{l}\text { Cholecystectomy and bile duct } \\
\text { exploration }\end{array}$ & 36 & 740 & $2 \mathrm{~h}, 30 \mathrm{~min}$ & $\begin{array}{l}\text { Wound } \\
\text { infection }\end{array}$ & 10 & 12 \\
\hline 5 & $\mathrm{~F}$ & 45 & Trauma & 21 & 430 & $2 \mathrm{~h}, 40 \mathrm{~min}$ & No event & 7 & 60 \\
\hline 6 & M & 54 & Liver hydatic surgery & 22 & 560 & $1 \mathrm{~h}, 40 \mathrm{~min}$ & $\begin{array}{l}\text { Left side } \\
\text { pneumonia }\end{array}$ & 12 & 108 \\
\hline 7 & M & 36 & $\begin{array}{l}\text { Cholecystectomy and bile duct } \\
\text { exploration }\end{array}$ & 21 & 130 & $2 \mathrm{~h}$ & No event & 8 & 12 \\
\hline 8 & $\mathrm{~F}$ & 64 & Liver hydatic surgery & 27 & 670 & $2 \mathrm{~h}, 25 \mathrm{~min}$ & No event & 7 & 48 \\
\hline 9 & M & 55 & $\begin{array}{l}\text { Cholecystectomy and bile duct } \\
\text { exploration }\end{array}$ & 25 & 800 & $2 \mathrm{~h}, 15 \mathrm{~min}$ & $\begin{array}{l}\text { Wound } \\
\text { infection }\end{array}$ & 11 & 36 \\
\hline 10 & $\mathrm{~F}$ & 38 & $\begin{array}{l}\text { Choledochojejunostomy anastomic } \\
\text { leak after whipple procedure }\end{array}$ & 20 & 590 & $1 \mathrm{~h}, 55 \mathrm{~min}$ & No event & 9 & 24 \\
\hline 11 & M & 41 & $\begin{array}{l}\text { Cholecystectomy and bile duct } \\
\text { exploration }\end{array}$ & 22 & 640 & $2 \mathrm{~h}, 30 \mathrm{~min}$ & No event & 8 & 36 \\
\hline 12 & $\mathrm{~F}$ & 62 & Trauma & 32 & 760 & $2 \mathrm{~h}, 10 \mathrm{~min}$ & No event & 8 & 72 \\
\hline $\begin{array}{l}\text { Mean } \\
\text { (Range) }\end{array}$ & & $47(33-64)$ & & $24(20-36)$ & $\begin{array}{l}573(400- \\
800)\end{array}$ & $\begin{array}{l}2 \mathrm{~h}, 15 \mathrm{~min}(1 \mathrm{~h}, \\
40 \mathrm{~min}-2 \mathrm{~h}, 50 \mathrm{~min})\end{array}$ & & $9(7-14)$ & $49(12-120)$ \\
\hline
\end{tabular}

Table 1: Descriptive characteristics of the patients. 
weeks in the literature [5]. So enough time must be allowed to these patients for spontaneous closure of the fistula. If the fistula can not be resolved by conservative approach, ERCP, MRCP and CT scan of biliary tract can be performed as a preparation to definitive operation. Those methods allow us to define especially the anatomical changes through the biliary tree and also the level of the fistula.

There were no mortalities in our series. These patients should be carefully prepared for the operation and preoperative close monitorization may be needed in some circumstances. All of our patients tolerated the operation well and multidisciplinary surgical team and high volume may affect the results of surgery. The success rate of fistulojejunostomy has been reported to be as high as $70 \%$ in a few published literature $[4,5,6]$. There were three patients in our series that moderate dilatation of intrahepatic biliary ducts were visualized by MRCP during postoperative course and in our knowledge, the dissection of the tract may have caused some degree fibrotic obstruction of the tract and that eventually caused that image. The use of fibrin sealants was not preferred for our patients since there has been no reports found to be of benefit in the management of external chronic refractory biliary fistula.

Also, the chance of revision on external biliary tree was dismal in our patients since they have had prior operations on hepatoduodenal ligamament and delineated anatomy did not allow us proper surgical dissection and identification of tissues for biliary revision procedures. On the other hand our method is not challenging since the operation is not associated with perioperative major complications and once the fistula tract successfully dissected and prepared, the biliary continuity was easily established for the distal part of the fistula tract. We have performed all anastomoses by using absorbable interrupted stitches and there were no major anastomotic problems in our series. One patient had a leak following the operation but that leak was spontaneously closed during postoperative course. In our technique we simply anastomosed the scar tube that developed around the abdominal drain to a Roux leg of small intestine. Our clinical outcomes, complication rates, operative parameters, blood loss etc are within acceptable limits. Only cholangitis was a little high but successfully treated with IV antibiotics. Postoperative complications were easily solved in our high volume center.

In this report we described our experience with fistulojejunostomy in the treatment of external chronic refractory biliary fistula when conventional surgical and minimal invasive approaches fail. That method can be easily applied by all experienced general surgeons although dissection of the perihepatic area can be fraught in the presence of scarring, inflammation etc. Our series is small and follow up period is short but long term data is needed for these patients. Fistulojejunostomy can be considered as a viable alternative for the patients with external chronic refractory biliary fistula fistula in those cases not amenable for conventional surgical or mininvasive procedures.

\section{References}

1. Adas G, Arikan S, Gurbuz E, Karahan S, Eryasar B, et al. (2010) Comparison of endoscopic therapeutic modalities for postoperative biliary fistula of liver hydatid cyst: a retrospective multicentric study. Surg Laparosc Endosc Percutan Tech 20: 223-227.

2. Pottakkat B, Vijayahari R, Prakash A, Singh RK, Behari A, et al. (2010) Factors predicting failure following high bilio-enteric anastomosis for postcholecystectomy benign biliary strictures. J Gastrointest Surg 14: 1389-1394.

3. Gilbo N, Mirabella S, Strignano P, Ricchiuti A, Lupo F, et al. (2009) External biliary fistula in orthotopic liver transplantation. Transplant Proc 41: 1316-1318.

4. Shostak VM, Shapryns'kyi VO, Mitiuk II (2007) Surgical treatment of biliary fistulas. Klin Khir: 11-13.

5. Salizzoni M, Romagnoli R, Mirabella S, Paraluppi G, Franchello A, et al. (2008) Intraoperative placement of transparietohepatic biliary drainage in remedial hepaticojejunostomy: technique and clinical experience. Am J Surg 195: 528532.

6. Yagci B, Parildar M, Oran I, Memis A (2007) Percutaneous interventional therapy of persistent biliary fistulas. Abdom Imaging 32: 475-480. 